\section{Case Reports in Nephrology and Dialysis}

Case Rep Nephrol Dial 2020;10:147-153

\begin{tabular}{l|l}
\hline DOI: $10.1159 / 000510147$ & (C) 2020 The Author(s)
\end{tabular}

Published online: November 4, 2020

Published by S. Karger AG, Basel www.karger.com/cnd

This article is licensed under the Creative Commons Attribution-NonCommercial 4.0 International License (CC BY-NC) (http://www.karger.com/Services/OpenAccessLicense). Usage and distribution for commercial purposes requires written permission.

\title{
Ewingella americana Peritonitis in a Patient on Peritoneal Dialysis: A Case Report and Review of the Literature
}

\author{
Shriya Khurana Christina Chemmachel Ramesh Saxena \\ Department of Internal Medicine, Division of Nephrology, University of Texas \\ Southwestern Medical Center, Dallas, TX, USA
}

\section{Keywords}

Ewingella americana $\cdot$ Peritonitis $\cdot$ Peritoneal dialysis

\begin{abstract}
Most episodes of peritoneal dialysis (PD)-associated peritonitis are caused by skin-dwelling gram-positive bacteria and gram-negative bacteria colonizing gut and urinary tract. Occasionally, however, uncommon bacteria can cause peritonitis in PD patients. We describe a case of Ewingella americana peritonitis, the first such case reported from the United States. A 68-yearold woman with end-stage kidney disease due to hypertension was initiated on PD 2 years prior to the present event. She presented with abdominal pain associated with nausea and vomiting. She was afebrile and hemodynamically stable. Abdomen was diffusely tender with guarding and rebound. No obvious root cause was apparent. Initial PD fluid white count was $502 / \mathrm{mm}^{3}$ with $87 \%$ neutrophils. Gram stain was negative. Culture grew gram-negative rods, which were later identified as Ewingella americana, resistant to ampicillin and cefazolin but sensitive to gentamicin, ceftazidime, and cefepime. After empiric intraperitoneal vancomycin and gentamicin, she was continued on intraperitoneal gentamicin for a total period of 21 days. She responded to the treatment rapidly with complete recovery. PD fluid on day four showed
\end{abstract}




\section{Case Reports in Nephrology and Dialysis}

40 nucleated cells with $12 \%$ neutrophils. Patient remained on PD without consequences. Ewingella americana is a gram-negative facultative anaerobic bacillus that can survive in water, including domestic water. Inadequate hand hygiene is a potential root cause of infection. Although rare, Ewingella peritonitis can be observed in PD patients and is treatable. Clinicians should be aware of Ewingella as a potential cause of PD peritonitis.

(C) 2020 The Author(s)

Published by S. Karger AG, Basel

\section{Introduction}

Peritonitis is a common and major complication of peritoneal dialysis (PD), at times leading to PD discontinuation. While the vast majority of peritonitis episodes in PD patients are caused by skin-dwelling gram-positive bacteria (Staphylococcus aureus, S. epidermidis, coagulase-negative staphylococci, streptococci) [1] and common gram-negative bacteria colonizing gut and urinary tract (Pseudomonas, Klebsiella, Proteus, Escherichia coli, Enterobacter) [2], PD patients occasionally get peritonitis from uncommon organisms [3]. Data regarding uncommon bacterial peritonitis (UBP) is sparse and thus prevalence, management, and outcome of UBP is not well known. Here, we present one such case of UBP caused by Ewingella americana. To our knowledge, this is the first case of Ewingella peritonitis reported from the United States. There have been two other reports of E. americana peritonitis in the past, one from Greece [4] and the other from China [5]. These cases will be reviewed in our case report.

\section{Case Report}

A 68-year-old African American woman with end-stage kidney disease due to hypertension was started on continuous cycler-assisted peritoneal dialysis (CCPD). She accidentally cut her catheter 2 months after initiation of PD. The catheter was promptly repaired in the clinic, prophylactic antibiotics given, and peritonitis prevented. About a year after initiating PD, she had an episode of peritonitis with Streptococcus mitis (oralis). It was attributed to not wearing mask while doing PD exchanges. It was successfully treated with intraperitoneal (IP) cefazolin.

On her present event, 2 years into CCPD, she came to the emergency department of a nearby hospital with nausea, vomiting, and abdominal pain. On presentation, she was afebrile and her vitals were stable - pulse: 86/min, BP: 109/68 mm Hg. Her abdomen was diffusely tender and positive for guarding and rebound tenderness.

The peritoneal dialysate was hazy and revealed a WBC count of 502 cells $/ \mathrm{mm}^{3}$, with a predominance of neutrophils (87\%). A repeat analysis on the following day showed 6,000 $\mathrm{WBCs} / \mathrm{mm}^{3}$ with $89 \%$ neutrophils. A diagnosis of peritonitis was made, and patient started on empiric vancomycin $1 \mathrm{~g}$ IP and gentamicin $40 \mathrm{mg}$ IP.

Gram staining of the dialysate was negative, but subsequent culture showed a growth of gram-negative rods after $48 \mathrm{~h}$ of incubation. The isolate was subsequently identified to be Ewingella americana, susceptible to ampicillin/sulbactam (Unasyn), piperacillin/tazobactam (Zosyn), ceftriaxone, ceftazidime, cefepime, gentamicin, levofloxacin, imipenem, and trimethoprim/sulphamethoxazole (Bactrim), but resistant to ampicillin, cefazolin, and cefuroxime. 


\section{Case Reports in Nephrology and Dialysis}

Case Rep Nephrol Dial 2020;10:147-153

DOI: $10.1159 / 000510147$

(c) 2020 The Author(s). Published by S. Karger AG, Basel www.karger.com/cnd

Khurana et al.: Ewingella americana Peritonitis in a Patient on Peritoneal Dialysis: A Case Report and Review of the Literature

Based on the antimicrobial susceptibility test results, patient was continued on $40 \mathrm{mg}$ IP gentamicin while vancomycin was discontinued. The patient improved dramatically by day 4 of hospital course, having a PD fluid WBC count of 40 cells $/ \mathrm{mm}^{3}$ with $12 \%$ neutrophils (Table 1). She remained hemodynamically stable, abdominal tenderness resolved, and she was discharged from the hospital on the fourth day. She was followed up in the PD clinic and completed a 3-week course of IP gentamicin. She had a rapid and complete recovery and was able to continue PD without any complications.

\section{Discussion}

Ewingella is a facultative anaerobic gram-negative bacillus belonging to the family Enterobacteriaceae, which was first described by Grimont et al. in 1983 [6]. Previously known as enteric group 40, the genus Ewingella includes only one species, E. americana. The organism is a rare human pathogen. Scattered reports of infections due to E. americana have appeared in the literature, documenting the pathogenic potential of this organism in humans [7-10]. The most common source of human isolates has been blood [9-11], but it has also been isolated from sputum [12], conjunctiva [8,13], and wounds [14]. E. americana can survive in citrate solution and is known to survive in water with simple nutritional requirements, including domestic water. Air conditioning units, ice baths, and wound cleaning devices serve as potential sources of infection $[4,5,9]$.

Earlier studies have suggested that Ewingella infects at-risk or predisposed people such as patients with prolonged hospitalization [7, 9], in postoperative period particularly after cardiovascular surgery $[9,10]$, those with indwelling catheters [11], and individuals with kidney failure $[4,5,12]$. Rare cases of PD-associated peritonitis have been reported $[4,5]$.

To our knowledge, this is the first reported Ewingella peritonitis case from the United States. Two other cases have been previously reported in the literature [4,5]. The first was in a 70-year-old Greek woman who had been on continuous ambulatory peritoneal dialysis (CAPD) for 5 years before developing Ewingella peritonitis [4]. The second was in a 76-yearold Chinese woman who developed the infection 10 months into CAPD [5]. Of note, all three cases of Ewingella peritonitis in PD patients have been in elderly females (Table 2). In all three cases, the organism was found to be non-susceptible to the commonly used empiric antibiotics (first and third generation cephalosporins and vancomycin) that target the common causes of PD peritonitis such as Staphylococcus aureus, coagulase-negative staphylococci, gut and urinary tract bacteria [3]. However, all patients had a favorable outcome with a complete course of the organism-specific antibiotic. A switch to hemodialysis was not needed in any case. This suggests that Ewingella peritonitis is a non-aggressive and treatable infection in PD patients.

While the root cause for the Ewingella PD peritonitis was not described in the previous cases, we thoroughly looked into it in our patient. Although it was not obvious in the current episode, her past history of accidentally cutting her catheter just 2 months into PD and an episode of Streptococcus oralis peritonitis a year after initiating PD, due to failure to wear a mask during PD, was suggestive of poor PD technique. Therefore, it is very likely that a break in the sterile technique due to patient's negligence and inadequate hygiene was the root cause of Ewingella americana peritonitis. Previous studies have shown that non-adherence to PD exchange protocols is significantly associated with peritonitis rate $[15,16]$. One study found 


\section{Case Reports in Nephrology and Dialysis}

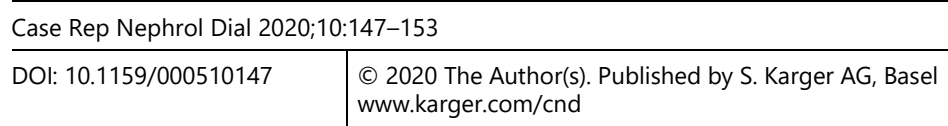

Khurana et al.: Ewingella americana Peritonitis in a Patient on Peritoneal Dialysis: A Case Report and Review of the Literature

that 6 months after the initiation of PD, most patients took shortcuts, modified the standard exchange method, or did not follow aseptic technique [17]. Since limited information on the natural habitat of this organism is available, we can only speculate on the source of Ewingella infection in our patient. Contaminated domestic water could have been the reservoir. Given prior history of poor sterile technique, inadequate hand hygiene could have resulted in the transmission of Ewingella americana from the reservoir to the peritoneum. Consequently, a home visit by PD nurse was re-conducted and the patient was advised to change the rusty showerhead. Moreover, the patient was re-trained on the aseptic techniques for the catheter and exit site care.

\section{Conclusion}

Ewingella, though rare, has pathogenic potential due to its ability to survive in water with minimal nutritional requirements. Domestic water is a potential source of infection.

It is mostly an opportunistic organism, and PD patients with their indwelling PD catheters can get infected from it, though in rare instances, likely due to break in sterile technique. $E$. americana peritonitis does not respond to the usual empiric antibiotics administered for the commonly encountered organisms in PD patients, but the infection is potentially treatable if a complete course of appropriate antibiotics, based on the antimicrobial sensitivity and susceptibility is administered. Clinicians should be aware of E. americana as a potential cause of peritonitis in PD patients.

\section{Statement of Ethics}

The study was conducted ethically in accordance with the World Medical Association Declaration of Helsinki (https://www.wma.net/policies-post/wma-declaration-of-helsinki-ethical-principles-for-medical-research-involving-human-subjects/). As the data for the study was obtained by retrospective chart review without direct contact with the patient, the requirement for informed consent was waived and the study was approved by the Institutional Review Board of the University of Texas Southwestern Medical Center, Dallas, Texas (STU 092017-026). As de-identified data based upon retrospective chart review was used, the requirement for consent was waived for the study.

\section{Conflict of Interest Statement}

The authors have no conflicts of interest to declare.

\section{Funding Sources}

This research received no specific grant from any funding agency in the public, commercial, or not-for-profit sectors. 


\section{Case Reports in Nephrology and Dialysis}

\begin{tabular}{l|l}
\hline Case Rep Nephrol Dial 2020;10:147-153 \\
\hline DOI: 10.1159/000510147 & $\begin{array}{l}\text { (c) 2020 The Author(s). Published by S. Karger AG, Basel } \\
\text { www.karger.com/cnd }\end{array}$
\end{tabular}

Khurana et al.: Ewingella americana Peritonitis in a Patient on Peritoneal Dialysis: A Case Report and Review of the Literature

\section{Author Contributions}

S.K. reviewed the literature and wrote the first draft of the manuscript. R.S. did the chart review to obtain patient data. All authors reviewed and edited the manuscript and approved the final version of the manuscript.

\section{References}

1 Brown F, Gulyani A, McDonald S, Hurst K. Chapter 6: Peritoneal Dialysis. In: McDonald S, Clayton P, Hurst K, editors. Australia and New Zealand Dialysis and Transplant Registry 35th Annual Report 2012 [Internet]. Adelaide, Australia: ANZDATA; 2012. Available from https://www.anzdata.org.au/report/anzdata-35thannual-report-2012/.

2 Wang HH, Huang CH, Kuo MC, Lin SY, Hsu CH, Lee CY, et al. Microbiology of peritoneal dialysis-related infection and factors of refractory peritoneal dialysis related peritonitis: A ten-year single-center study in Taiwan. J Microbiol Immunol Infect. 2019 Oct;52(5):752-9.

3 Li PK, Szeto CC, Piraino B, de Arteaga J, Fan S, Figueiredo AE, et al. ISPD Peritonitis Recommendations: 2016 Update on Prevention and Treatment. Perit Dial Int. 2016 Sep;36(5):481-508.

4 Kati C, Bibashi E, Kokolina E, Sofianou D. Case of peritonitis caused by Ewingella americana in a patient undergoing continuous ambulatory peritoneal dialysis. J Clin Microbiol. 1999 Nov;37(11):3733-4.

5 Li L, Shen J, Tao J, Xue Z. Peritonitis caused by Ewingella americana in a patient with peritoneal dialysis: a case report. J Med Case Reports. 2014 Mar;8(1):86.

6 Grimont PA, Farmer JJ 3rd, Grimont F, Asbury MA, Brenner DJ, Deval C. Ewingella americana gen.nov., sp.nov., a new Enterobacteriaceae isolated from clinical specimens. Ann Microbiol (Paris). 1983 JanFeb;134A(1):39-52.

7 Devreese K, Claeys G, Verschraegen G. Septicemia with Ewingella americana. J Clin Microbiol. 1992 Oct;30(10):2746-7.

8 Heizmann WR, Michel R. Isolation of Ewingella americana from a patient with conjunctivitis. Eur J Clin Microbiol Infect Dis. 1991 Nov;10(11):957-9.

9 Pien FD, Bruce AE. Nosocomial Ewingella americana bacteremia in an intensive care unit. Arch Intern Med. 1986 Jan;146(1):111-2.

10 Pien FD, Farmer JJ 3rd, Weaver RE. Polymicrobial bacteremia caused by Ewingella americana (family Enterobacteriaceae) and an unusual Pseudomonas species. J Clin Microbiol. 1983 Sep;18(3):727-9.

11 Maertens J, Delforge M, Vandenberghe P, Boogaerts M, Verhaegen J. Catheter-related bacteremia due to Ewingella americana. Clin Microbiol Infect. 2001 Feb;7(2):103-4.

12 Ryoo NH, Ha JS, Jeon DS, Kim JR, Kim HC. A case of pneumonia caused by Ewingella americana in a patient with chronic renal failure. J Korean Med Sci. 2005 Feb;20(1):143-5.

13 Da Costa PS, Tostes MM, de Carvalho Valle LM. A case of keratoconjunctivitis due to Ewingella americana and a review of unusual organisms causing external eye infections. Braz J Infect Dis. 2000 Oct;4(5):262-7.

14 Bear N, Klugman KP, Tobiansky L, Koornhof HJ. Wound colonization by Ewingella americana. J Clin Microbiol. 1986 Mar;23(3):650-1.

15 Russo R, Manili L, Tiraboschi G, Amar K, De Luca M, Alberghini E, et al. Patient re-training in peritoneal dialysis: why and when it is needed. Kidney Int Suppl. 2006 Nov;70(103):S127-32.

16 Mawar S, Gupta S, Mahajan S. Non-compliance to the continuous ambulatory peritoneal dialysis procedure increases the risk of peritonitis. Int Urol Nephrol. 2012 Aug;44(4):1243-9.

17 Dong J, Chen Y. Impact of the bag exchange procedure on risk of peritonitis. Perit Dial Int. 2010 JulAug;30(4):440-7. 
Case Reports in Nephrology and Dialysis
Case Rep Nephrol Dial 2020;10:147-153

\begin{tabular}{l|l}
\hline DOI: $10.1159 / 000510147$ & ( 2020 The Author(s). Published by S. Karger AG, Basel
\end{tabular} www.karger.com/cnd

Khurana et al.: Ewingella americana Peritonitis in a Patient on Peritoneal Dialysis: A Case Report and Review of the Literature

Table 1. Peritoneal fluid analysis

\begin{tabular}{llll}
\hline Peritoneal fluid & Day 1 & Day 2 & Day 4 \\
\hline Color & Straw & Yellow & Yellow \\
Turbidity & Hazy & Hazy & Clear \\
RBC count $\left(/ \mathrm{mm}^{3}\right)$ & 20 & 70 & 0 \\
WBC count $\left(/ \mathrm{mm}^{3}\right)$ & 502 & 6,000 & 40 \\
Lymphocyte, $\%$ & 1 & 1 & 14 \\
Neutrophil, \% & 87 & 89 & 12 \\
Monocyte, $\%$ & 10 & 10 & 69 \\
\hline
\end{tabular}




\section{Case Reports in Nephrology and Dialysis}

Table 2. Case reports of Ewingella americana peritonitis in PD patients reported worldwide

\begin{tabular}{|c|c|c|c|}
\hline & Case 1 [4] & Case 2 [5] & Case 3 [present study] \\
\hline Age, years & 70 & 76 & 68 \\
\hline Gender & Female & Female & Female \\
\hline Ethnicity & Greek & Chinese & African American \\
\hline Cause of ESKD & Polycystic kidney disease & Not specified & Hypertension \\
\hline PD schedule & $\begin{array}{l}\text { Continuous ambulatory } \\
\text { peritoneal dialysis }\end{array}$ & $\begin{array}{l}\text { Continuous ambulatory } \\
\text { peritoneal dialysis }\end{array}$ & $\begin{array}{l}\text { Continuous cycler-assisted } \\
\text { peritoneal dialysis }\end{array}$ \\
\hline $\begin{array}{l}\text { Previous peritonitis } \\
\text { episodes }\end{array}$ & Unknown & Unknown & $\begin{array}{l}\text { Streptococcus oralis } \\
\text { peritonitis }\end{array}$ \\
\hline $\begin{array}{l}\text { Duration of } \mathrm{PD} \text { (prior to } \\
\text { Ewingella peritonitis) }\end{array}$ & 5 years & 10 months & 2 years \\
\hline Root cause & Not identified & Unknown & $\begin{array}{l}\text { Likely break in sterile } \\
\text { technique }\end{array}$ \\
\hline Presenting symptoms & $\begin{array}{l}\text { Diffuse abdominal pain, } \\
\text { fever }\end{array}$ & $\begin{array}{l}\text { Generalized abdominal } \\
\text { pain, decreased appetite, } \\
\text { left chest pain and pressure - } \\
\text { worse at night }\end{array}$ & $\begin{array}{l}\text { Diffuse abdominal pain, } \\
\text { nausea, vomiting }\end{array}$ \\
\hline Signs on physical exam & $\begin{array}{l}\text { Abdominal tenderness, } \\
\text { positive rebound }\end{array}$ & $\begin{array}{l}\text { Abdominal tenderness, } \\
\text { positive rebound }\end{array}$ & $\begin{array}{l}\text { Abdominal tenderness, } \\
\text { guarding }+ \text {, rebound }+\end{array}$ \\
\hline Dialysate & $\begin{array}{l}\text { Turbid, } 400 \mathrm{WBCs} / \mathrm{mm}^{3} \\
\text { with neutrophil predomi- } \\
\text { nance }\end{array}$ & $\begin{array}{l}\text { Turbid, } 400 \mathrm{WBCs} / \mathrm{mm}^{3} \\
\text { with neutrophil predomi- } \\
\text { nance }\end{array}$ & $\begin{array}{l}\text { Hazy, initial } 502 \text {, later } 6,000 \\
\text { WBCs } / \mathrm{mm}^{3} \text { with neutrophil } \\
\text { predominance }\end{array}$ \\
\hline Empiric antibiotic used & $\begin{array}{l}\text { Intravenous vancomycin } \\
\text { and amikacin }\end{array}$ & Intravenous vancomycin & $\begin{array}{l}\text { IP vancomycin and } \\
\text { gentamicin }\end{array}$ \\
\hline Antibiotic susceptibility & $\begin{array}{l}\text { Ampicillin, amoxicillin - } \\
\text { clavulanate, ceftazidime, } \\
\text { ceftriaxone, cefotaxime, } \\
\text { cefepime, ofoxacin, } \\
\text { gentamicin, carbenicillin, } \\
\text { amikacin }\end{array}$ & $\begin{array}{l}\text { Tobramycin, ceftazidime, } \\
\text { cefepime, aztreonam, } \\
\text { imipenem, amikacin, } \\
\text { gentamicin, ciprofloxacin, } \\
\text { piperacillin, levofloxacin }\end{array}$ & $\begin{array}{l}\text { Ampicillin-sulbactam, } \\
\text { piperacillin-tazobactam, } \\
\text { ceftriaxone, ceftazidime, } \\
\text { cefepime, gentamicin, levo- } \\
\text { floxacin, imipenem, trimetho- } \\
\text { prim-sulphamethoxazole }\end{array}$ \\
\hline Antibiotic resistance & $\begin{array}{l}\text { Cephalothin, penicillin } \mathrm{G} \text {, } \\
\text { vancomycin }\end{array}$ & $\begin{array}{l}\text { Ampicillin, ampicillin- } \\
\text { sulbactam, cefazolin, } \\
\text { cefotetan, ertapenem, tri- } \\
\text { methoprim-sulfamethoxazole, } \\
\text { nitrofurantoin }\end{array}$ & $\begin{array}{l}\text { Ampicillin, cefazolin, } \\
\text { cefuroxime }\end{array}$ \\
\hline Management & $\begin{array}{l}\text { Vancomycin discontinued, } \\
\text { continued on amikacin }\end{array}$ & $\begin{array}{l}\text { Vancomycin switched to } \\
\text { amikacin }\end{array}$ & $\begin{array}{l}\text { Vancomycin discontinued, } \\
\text { gentamicin continued }\end{array}$ \\
\hline $\begin{array}{l}\text { Duration of antibiotic } \\
\text { treatment }\end{array}$ & $\begin{array}{l}\text { Amikacin administered } \\
\text { until complete recovery }\end{array}$ & $\begin{array}{l}\text { Amikacin administered until } \\
\text { complete patient recovery }\end{array}$ & $\begin{array}{l}\text { Gentamicin given for a total } \\
\text { period of } 3 \text { weeks }\end{array}$ \\
\hline Outcome & Complete recovery & Complete recovery & $\begin{array}{l}\text { Complete recovery, patient } \\
\text { continued on PD without } \\
\text { complications }\end{array}$ \\
\hline
\end{tabular}

ESKD, end-stage kidney disease; PD, peritoneal dialysis; IP, intraperitoneal. 